\title{
$0^{-\min }$
}

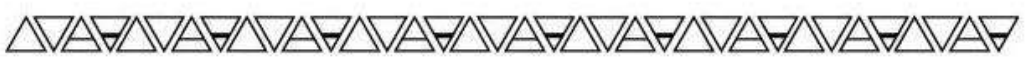

DOI 10.31418/2177-2770.2020.v12.n.31.p133-151| ISSN 2177-2770

Licenciado sob uma Licença Creative Commons

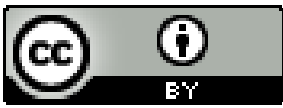

O PAN-AFRICANISMO EM ABDIAS DO NASCIMENTO E A PROPOSTA DE DESCOLONIZAÇÃO

\author{
Luís Thiago Freire Dantas ${ }^{1}$
}

\begin{abstract}
Resumo: A importância de José Abdias do Nascimento para a formação da intelectualidade brasileira consiste em uma inspiração à luta antirracista da população negra brasileira. A sua produção intelectual problematizou as nuances do racismo antinegro no Brasil e articulou formas de resistência diante do apagamento da história negroafricana brasileira. Partindo de tais teses relacionamos com a proposta de descolonização de Nkolo Foé em oposição ao epistemicídio direcionado à filosofia africana. Com isso, no primeiro momento, o enfoque consistirá na concepção de Pan-africanismo através de teóricos como Marcus Garvey e Kwame Nkrumah. Por fim, retomar o pensador brasileiro através das teses presentes no Quilombismo para pensar em conjunto com a filosofia africana de Nkolo Foé a resistência política-filosófica ao racismo anti-negro.
\end{abstract}

Palavras-Chaves: Descolonização; Epistemicídio; Pan-africanismo; Quilombismo; Racismo anti-negro.

\section{PANAFRICANISM IN ABDIAS DO NASCIMENTO AND THE PROPOSAL OF DECOLONIZATION}

\begin{abstract}
The importance of José Abdias do Nascimento for the formation of the Brazilian intelligentsia is an inspiration to the anti-racist struggle of the Brazilian black population. His intellectual production problematized the nuances of anti-black racism in Brazil and articulated forms of resistance to the erasure of Brazilian black-African history. Based on these theses we relate to Nkolo Foé's proposal for decolonization in opposition to the episthemicide directed at African philosophy. Thus, at first, the focus will be on the conception of Pan-Africanism through theorists such as Marcus Garvey and Kwame Nkrumah. Finally, to resume the Brazilian thinker through the theses present in Quilombismo to think together with the African philosophy of Nkolo Foé the politicalphilosophical resistance to anti-black racism.
\end{abstract}

Keywords: Decolonization; Epistemicide; Pan-Africanism; Quilombismo; Anti-black racism.

PANANFRICANISMO EN ABDIAS DO NASCIMENTO Y LA PROPUESTA DE DESCOLONIZACIÓN

1 Doutor em Filosofia pela UFPR. Professor de Filosofia da Educação da UERJ. E-mail: fdthiago@gmail.com

Revista da ABPN • v. 12, n. $31 \cdot \operatorname{dez} 2019$ - fev 2020, p. 133-151 
Resumen: La importancia de José Abdias do Nascimento para la formación de la intelectualidad brasileña es una inspiración para la lucha antirracista de la población negra brasileña. Su producción intelectual problematizó los matices del racismo anti-negro en Brasil y articuló formas de resistencia a la eliminación de la historia brasileña negraafricana. En base a estas tesis, nos relacionamos con la propuesta de Nkolo Foé para la descolonización en oposición al epistemicídio dirigido a la filosofía africana. Así, al principio, la atención se centrará en la concepción del panafricanismo a través de teóricos como Marcus Garvey y Kwame Nkrumah. Finalmente, retomar al pensador brasileño a través de las tesis presentes en el Quilombismo para pensar junto con la filosofía africana de Nkolo Foé la resistencia político-filosófica al racismo anti-negro.

Palabras Claves: Descolonización; Epistemicídio; Panafricanismo; Quilombismo; Racismo anti-negro.

\section{LE PANAFRICANISME DANS ABDIAS DO NASCIMENTO ET LA PROPOSITION DE DÉCOLONISATION}

Resumé: L'importance de José Abdias do Nascimento pour la formation de l' intelligentsia brésilienne est une inspiration pour la lutte antiraciste de la population noire brésilienne. Sa production intellectuelle a problématisé les nuances du racisme anti-noir au Brésil et articulé des formes de résistance à l'effacement de l'histoire noire-africaine brésilienne. À partir de ces thèses, nous nous rapportons à la proposition de décolonisation de Nkolo Foé en opposition à l'épistémicide dirigé vers la philosophie africaine. Ainsi, dans un premier temps, l'accent sera mis sur la conception du panafricanisme à travers des théoriciens tels que Marcus Garvey et Kwame Nkrumah. Enfin, reprendre le penseur brésilien à travers les thèses présentes dans le Quilombismo pour réfléchir avec la philosophie africaine de Nkolo Foé à la résistance politico-philosophique au racisme antinoir.

Mots-Clé: Décolonisation; Épistémicide; Panafricanisme; Quilombismo; Racisme antinoir.

\section{INTRODUÇÃO}

A atividade de José Abdias do Nascimento para uma luta antirracista não se trata somente de uma contribuição localizada no tempo histórico, mas ultrapassa várias barreiras e até hoje possui uma importância ímpar. Entretanto, a academia brasileira não oferece uma atenção devida às teses desenvolvidas por Abdias do Nascimento ${ }^{2}$.

Com isso, o presente artigo faz e propõe uma reflexão a partir de algumas teses desse pensador negro e brasileiro que não distanciou de si a militância. Sabendo que o

\footnotetext{
${ }^{2}$ Para um aprofundamento no legado histórico e biográfico de Abdias do Nascimento ver Carlos Roberto do Nascimento (2015).
} 
espaço desse artigo não supre a ausência de estudos sobre as teses "nascimentistas" o caminho escolhido consistirá em detalhar a influência do pan-africanismo ao pensamento de Abdias do Nascimento e observar como as suas teses proporcionam uma atividade de descolonização teórica-político. Algumas perguntas servem de guias para a construção do artigo: Como o pan-africanismo permitiu a Abdias construir um arcabouço teórico contra o racismo anti-negro? Quais teóricos pan-africanistas são possíveis de observar no pensamento de Abdias de Nascimento?

Partindo de tais questões este artigo inicialmente tece algumas passagens deste autor que fundamentam a luta contra a ideologia da democracia racial brasileira. Principalmente por se tratar de uma ideologia com o propósito de ocultar o problema do racismo por mais que historicamente ele tenha se alojado como um problema estrutural da sociedade brasileira. Em seguida, o artigo trata de alguns pensadores pan-africanistas, por fim relacionar a perspectiva política de Nkolo Foé com teses do Quilombismo tendo como proposta uma atividade descolonial.

\section{REFUTAÇÃO À IDEOLOGIA DA DEMOCRACIA RACIAL}

$\mathrm{Na}$ leitura de obras como o Genocídio do Negro Brasileiro (2016) e do Quilombismo (2019) rapidamente percebemos como Abdias de Nascimento construiu tais livros como forma de manifesto para denunciar o extermínio da população negra no Brasil que diverge da imagem de democracia racial no território brasileiro. Uma imagem que atua enquanto modo de impedir qualquer atividade da população negra a respeito de uma discordância ou requerimento de direitos. Acerca disso Abdias problematiza da seguinte maneira:

Em verdade, em verdade, porém, a camada dominante simplesmente considera qualquer movimento de conscientização afro-brasileira como ameaça ou agressão retaliativa. E até mesmo se menciona que nessas ocasiões os negros estão tratando de impor ao país uma suposta superioridade racial negra (NASCIMENTO, 2016, p. 93).

Nesse caminho, podemos afirmar que a sociedade brasileira incutiu em si mesmo a tendência à mansidão e ao conformismo baseados em uma interpretação do mundo como a serviço do destino. Essa interpretação ultrapassa a imagem da democracia racial e se põe como julgamento histórico da colonização sobre os povos africanos: “O drama 
da África é que o homem africano não entrou totalmente na história [...] Nunca ele se lança em direção ao futuro. Nunca não lhe vem à ideia de sair da repetição para se inventar um destino"(SARKOZY apud FOE, 2013, p. 178). O discurso de Sarkozy fora realizado em Dakar-Senegal no início deste século, distante temporalmente das críticas de Abdias à harmonia racial brasileira, mas que fazem tais críticas serem atemporais, principalmente quando se pensa a emancipação dos povos negros:

A luta comum dos povos negros e africanos requer o conhecimento mútuo e uma compreensão recíproca que nos têm sido negados, além de outros motivos, pelas diferentes línguas que o opressor branco-europeu impôs sobre nós, através do monopólio dos meios de comunicação, do seu controle exclusivo dos recursos econômicos, das instituições educativas e culturais. Tudo isto tem permanecido a serviço da manutenção da supremacia racial branca (NASCIMENTO, 1980, p. $15)$.

No caso brasileiro, a contraposição refere-se à ideologia retirada da obra de Gilberto Freyre que formula o conceito de "metarraça" que estaria na base da consciência brasileira. Freyre constrói esse conceito para articular uma ideia de pacifismo inerente ao conjunto de "raças" que povoam o Brasil. Tal conjunto promove uma "morenidade metarracial" que "oposta aos conceitos fornecidos por arianismo e negritude, ambos classificados como racistas por Gilberto Freyre" (NASCIMENTO, 2016, p. 44). Por isso, Abdias Nascimento explica que há uma ideologia que dificulta o enfrentamento a tal entendimento por provocar "inconvenientes" ao negro que se revolta na sociedade brasileira como as subversivas "atividades raciais" que provoca o divisionismo das classes:

O objetivo não expresso dessa ideologia é negar ao negro a possibilidade de autodefinição, subtraindo-lhe os meios de identificação racial. Embora na realidade social o negro seja discriminado exatamente por causa de sua raça e da cor, negam a ele, com fundamentos na lei, o direito legal da autodefesa. (NASCIMENTO, 2016, p. 94).

Por tais aspectos, Abdias explica a intenção última da democracia racial como meios dos povos se identificarem como contributos ao exercício racional da humanidade. Entre as maneiras para atribuir desconfianças às próprias potencialidades se encontra a dificuldade em assumir racialmente por serem colocados à armadilha: "todo mundo é simplesmente brasileiro". Consequentemente há uma negação do direito legal da autodefesa "nenhum meio legal de protesto, de busca de alívio contra a injustiça racial, existe para o grupo discriminado e oprimido, desde que a lei- formal e distante- recolhe a todos em seu seio “democrático"” (NASCIMENTO, 2016, p. 79). Tais vozes silenciadas, 
para o autor, dizia respeito "aqueles que agora se encontram no cárcere por causa de sua militância em favor de uma revolução negra ou pan-africana" (NASCIMENTO, 2019, p. 92).

Para ressoar tais vozes que compunham uma "revolução pan-africana" é importante detalhar as características teóricas do pan-africanismo que influenciaram Abdias do Nascimento e, assim permitiu realizar uma atuação global como bem destaca Carlos Moore (2008, p. 237) sobre a contribuição "nascimentista":

Para melhor apreender a contribuição do 'nascimentista', é necessário esclarecer, de início, que se trata, por um lado, de um discurso voluntarista e desconstrutor e, por outro, de uma ação de síntese e renovação das diferentes vertentes que compõem o movimento pan-africanista mundial, no intento de adequá-las às exigências do mundo contemporâneo. É um discurso-prática em que ação e reflexão avançam em paralelo, entrechocando-se, recombinando-se seletivamente e partindo para novas desconstruções.

Nessa passagem de Carlos Moore apreendem-se certas posições, que as teses "nascimentistas" dizem respeito a um discurso voluntarista e desconstrutor e, ao mesmo tempo, busca uma adequação das teses pan-africanistas às exigências contemporâneas. Tal adequação parte um duplo setor de intelectuais pan-africanistas que interrogam do continente e desde a diáspora a presença africana no mundo. Por esse aspecto, a próxima seção se deterá em dois filósofos que representam a sua maneira teses pan-africanas: Marcus Garvey e Kwame Nkrumah.

\section{O PAN-AFRICANISMO DE GARVEY E NKRUMAH}

A expressão "pan-africanismo" entrou no vocabulário intelectual no começo do século XX por meio da atuação de Henry Sylvester-Williams, de Trinidade, e William DuBois, dos Estados Unidos da América, ambos de ascendência africana, em diversos congressos pan-africanos. Tais congressos tinham como participantes vários intelectuais negros tanto do continente africano quanto da diáspora. Um dos que contribuíram para o nacionalismo africano fora Marcus Garvey através do movimento de "regresso a África".

Garvey fora um jamaicano que conduziu uma enorme influência a vários intelectuais por propor um "olhar sobre a própria história" não a deixando ser formada por ideólogos que conduziram a história do continente africano como subordinada à 
história europeia. Inclusive, os povos negros ao não assumirem os próprios feitos criam um imaginário que existe uma deficiência intelectual, política e social em si mesmos. Garvey adverte para tal imaginário como consequência de uma falta de representativa na história:

\begin{abstract}
Chega o tempo do Negro para esquecer o elenco expresso por trás dele o culto a heróis e adoração a outras raças, e iniciar a partir de imediatamente, a criar e emular heróis de sua autoria. Nós devemos canonizar nossos próprios santos, criar nossos próprios mártires, e eleva-los a posições de fama e honra, homens e mulheres negros que construíram suas distintas contribuições para nossa história racial. Sojouner Truth é digno de um lugar de santidade ao lado de Joana d'Arc; Crispo Attucks e George William Gordon têm o direito a auréola de martírio com nada menos que a glória de outros mártires de qualquer outra raça. Toussaint L'Overture's brilhou como um soldado e estadista ofuscado por Cromwell, Napoleão e Washington; por isso, ele tem direito ao lugar mais alto como um herói entre os homens. África produziu um número incontável de homens e mulheres, na guerra e na paz, cujo o brilho e bravura ofusca o brilho de qualquer outro povo. Então, por que não ver o bem e a perfeição em nós mesmos? (GARVEY, 2016).
\end{abstract}

A dificuldade em enxergar o bem e a perfeição com uma extensão de si mesmos consiste em uma forma de se perceber no mundo por meio da falta: "O mundo branco, o único honesto, rejeitava minha participação [...] Eu acenava para o mundo e o mundo amputava meu entusiasmo. Exigiam que eu me confinasse, que encolhesse" (FANON, 2008, p. 107). Para contrariar essa condição, Garvey afirma que os povos negros a partir do momento que têm a percepção do "bem e perfeição" como atributos próximos de si, possibilita a formação de um "império negro". Acerca disto, o projeto é de uma organização negra que produzirá um domínio no continente africano, já que para o autor “é só uma questão de mais alguns anos, quando a África estará totalmente colonizada pelos negros, como a Europa é pela raça branca" (GARVEY, 2013, p. 109). Por esse aspecto ocorre uma expectativa de união de diferentes povos negros ao redor do mundo para a promoção de uma "Nacionalidade Africana Independente". A presença da população negra das Américas e das Índias Ocidentais no continente africano, não consistiria, para Garvey, em uma submissão dos africanos a estes povos, mas teria a finalidade de construir uma "Associação Universal para o Progresso do Negro" e tendo a África como base fundamental para uma cooperação fraterna entre os negros africanos, americanos e das Índias Ocidentais: "vamos entrar em uma parceria para erguer a África nos interesses da nossa raça" (GARVEY, 2013, p. 109). 
Se Marcus Garvey representaria a influência "desconstrutora" do pensamento de Abdias do Nascimento, o outro lado da "renovação" concentraria nas teses políticas de Kwame Nkrumah. Nkrumah fora o presidente de Gana após a independência do país do jugo colonial, com isso um país africano teria como presidente um filósofo e ativista político que procuraria justamente a independência do continente africano das amarras imperialistas e coloniais que ainda permaneceram durante o neocolonialismo. Por esse modo, Nkrumah escreve vários livros entre os quais se destaca África deve se unir e

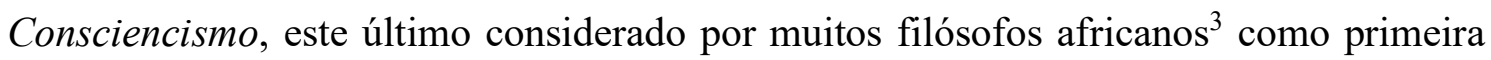
grande obra da filosofia africana. No que se refere a unidade africana, Nkrumah aponta para a necessidade de três setores - raça, cultura e língua comum - por mais que houvesse uma tentativa de separação dos povos africanos:

Estou convencido de que as forças que atuam a favor da unidade aventajam às que nos separam. Ao reunir-me com companheiros africanos de todas as partes do continente, sempre me impressiona quanto temos de comum. Não é só nosso passado colonial ou o direito de que nos propagamos objetivos comuns: é algo muito mais profundo. Pode descrever-se do melhor modo como um sentido de unicidade ao africano (NKRUMAH, 1965, p. 182).

Assim, a necessidade de uma unidade africana consiste em uma das principais motivações dos pan-africanos em sua amplitude teórica. De tal maneira que no ano de 1960, Nkrumah junto com Sekou Touré de Guiné e Modibo Keita de Mali discutiram o problema da emancipação da unidade africana que se destaca em um compartilhamento de compromissos:

Não vejo segurança para os estados africanos a menos que os dirigentes africanos, como nós mesmos, tenham compreendido, sem espaço de dúvidas, que para a África a salvação está na unidade. Porque a união faz a força e, tal como vejo, os Estados africanos devem unir-se ou se venderem aos exploradores imperialistas e colonialistas por um prato de comida, ou bem desintegrar-se individualmente (NKRUMAH, 1960, p. 196-197).

Para impedir tal acontecimento, de acordo com Nkrumah, o continente africano necessita emancipar-se das amarras colonialistas e estabelecer a contribuição de seus povos para o desenvolvimento do que seria a humanidade, pois a ocorrência da emancipação do continente africano confirma também a emancipação do humano.

\footnotetext{
${ }^{3}$ Paul Hountondji reserva no livro Sur la Philosophie Africaine um longo estudo sobre a influência do Consciencismo para a filosofia africana.
} 
Por essa emancipação percebe-se uma proximidade com as teses de Abdias de Nascimento que lutava contra a ideologia da democracia racial que oculta e invalidade uma luta antirracista negra, inclusive propiciando um exercício de uma política descolonial.

\section{ELEMENTOS QUILOMBISTAS DE DESCOLONIZAÇÃO}

O exercício da descolonização se constrói a partir de uma luta de autoafirmação, principalmente quando se espera que as linguagens, os métodos, as interpretações de mundo necessitem se fundamentar em discursos tratados como cânones, ou faz parte de uma geografia hegemônica. Isso pode ser exemplificado através da percepção de não-ser que a população negra passa a ser vista em sua relação com a branca, já que, conforme as palavras de Sueli Carneiro, "a negação da identidade, da racialidade negra, no qual a miscigenação é um operador, implica o plano político em destituir o negro [e a negra] da condição de um grupo de interesse, a ser reconhecido, é uma estratégia de controle e anulação do sujeito político" (CARNEIRO, 2005, p. 282). E essa atribuição de não-ser invade a mente de tal população que nessa autorecusa provoca aquilo que Abdias do Nascimento define como "mentecídio":

Entre os mecanismos executores do linchamento social do afro-brasileiro deixando de lado a miscigenação compulsória, que significa o embranquecimento forçado do negro [e da negra] como único meio da melhoria sócio-econômica; indo além do preconceito de cor, da discriminação e da segregação raciais, os supremacistas brancos e brancóides manejam simultaneamente outras ferramentas de controle social do povo negro, exercendo sobre ele constante lavagem cerebral, visando entorpecer ou castrar sua capacidade de raciocínio. Esta tarefa vil quase não encontra obstáculos à sua frente, devido à situação de permanente penúria, fome, degradação física e moral, em que são mantidas as massas afro-brasileiras. Esta forma de mentecídio contribui muito significativamente para o resultado ótimo buscado pela estratégia do seu aniquilamento total (NASCIMENTO, 1980, p. 25).

Assim, as teses de Nascimento expõem uma resistência perante essa "estratégia do seu aniquilamento total", especificamente no Quilombismo que propicia examinar o movimento do epistemicídio na sociedade diaspórica africana como efeito de um racismo epistêmico: "Não se trata do problema de introduzir um novo e não provado conhecimento para preencher um suposto vazio que importa, mas de renovar, criticar, 
ampliar e atualizar nosso conhecimento já existente" (NASCIMENTO, 2019, p. 66, grifos do autor).

O conhecimento de África para quem está na diáspora, de acordo o autor, sempre se deu a partir de uma ciência de base eurocêntrica. O problema é que tal ciência observa o "Outro" como não adequado a tal base. Por esse modo há um entendimento comum de que as tradições africanas seriam ausentes de uma racionalidade "científica" e com uma economia "primitiva" que teria um desenvolvimento "imóvel". Nascimento refuta tal antecipação dogmática, pois "todo o conhecimento que se tem dessas culturas demonstra o oposto desse imobilismo que lhe querem impingir, como a própria razão de ser da produção cultural africana" (NASCIMENTO, 2002, p. 55). Em sentido contrário, para o autor, a cultura ocidental está em volta de si mesma por haver uma exaustão histórica que a torna incapaz de impedir a própria decadência. Por esse modo, de maneira acentuada, uma produção de "política de inimizade" teria como objetivo o extermínio do Outro para manter em funcionamento a própria cultura ${ }^{4}$. Exatamente por essa via que o cientificismo ocidental procurou distorcer as visões de africanos e dos seus descendentes diaspóricos sobre a própria personalidade humana. Em resposta a tais distorções, Nascimento constrói, a partir do conceito de Quilombismo, um projeto científico histórico-social para uma revolução pan-africana. Sobre isso o autor elenca alguns elementos organizados aqui em tópicos:

Libertação da personalidade humana, sem a abdicação de sua responsabilidade como um ser histórico. Os homens e mulheres africanos devem demonstrar a si mesmos que são capazes de transformar as circunstâncias nas quais eles vivem; e que tendo sido um povo que foi submetido e conduzido por Outros recuperou a capacidade de conduzir seu próprio destino. Eles podem e desejam libertar a si mesmos daqueles instrumentos estrangeiros, de dominação que no passado os oprimiram e alienaram; e que vigorosa e decididamente rejeitam todas as forças de exploração e submissão (NASCIMENTO, 2019, p. 67).

Partindo desses elementos, o Quilombismo torna-se possível para uma oposição aos campos ideológicos que impuseram o colonialismo como fundamental para a saída

\footnotetext{
${ }^{4}$ Não é gratuito que esse início de século transpareça em várias partes do globo inúmeros discursos de conteúdo de indiferença do Outro, principalmente atribuindo ao Outro as mazelas socioeconômicas dos países. Por esse aspecto, promove-se uma "política de inimizade", pelo fato de que "o terror colonial se intercala constantemente com um imaginário colonialista de terras selvagens e mortes, e com ficções que criam a ilusão do real. A paz não é necessariamente a consequência natural de uma guerra colonial. Na verdade, a distinção entre guerra e paz não é relevante. As guerras coloniais são concebidas como a expressão de uma hostilidade absoluta, que coloca o Conquistador diante de um inimigo absoluto" (MBEMBE, 2011, p. 41).
} 
do imobilismo atribuído aos "Outros". Assim, os elementos destacados por Nascimento serão compreendidos por meio de uma aproximação interpretativa com Nkolo Foé (2013) que analisa a "desconexão do corpo do império" e a "retomada da iniciativa histórica". E posteriormente a tal aproximação será analisado neste texto como o Quilombismo pode ser interpretado como uma forma de "descolonização epistêmica".

No primeiro ponto do Quilombismo, "libertação da personalidade humana, sem a abdicação de sua responsabilidade como um ser histórico" (NASCIMENTO, 2002, p. 67), o autor explica como os processos de independência das colônias africanas permitiram uma conquista de liberdade e de melhorias socioeconômicas, mas tais esforços precisariam ser meticulosos devido à estratégia de separação oriunda do colonialismo e do racismo. Com isso, "novos passos devem ser resolutamente dados na direção a uma estratégia de progresso e de completa libertação, tendo em vista os objetivos de comunhão entre os povos irmãos do continente" (NASCIMENTO, 2002, p. 81), pois reservar as riquezas do país a uma elite somente ratificaria as atuações do neocolonialismo.

Acrescentado a isso, Foé indica "a desconexão do corpo do império" como finalidade de integrar "os indivíduos e [...] nações da África e do Sul em um grande projeto universal comum, na independência, na igualdade e na reciprocidade" (FOE, 2013, p. 219, grifos do autor). Entretanto, o universal presente em tal objetivo diverge da compreensão habitual de uma "matéria primitiva" ou de "essências brutas das culturas"; ao contrário, diz respeito ao "núcleo substancial e racional das culturas" (FOE, 2013, p. 219) de maneira que na diferença de culturas permite-se um intercâmbio equânime de ideias e de costumes. Apesar desse "núcleo substancial" ainda permanecer orientado por uma assimetria, pois há "um trabalho do negativo sobre a substância imediata, primitiva dos costumes, das tradições antigas, dos saberes populares, dos mitos arcaicos, das religiões ancestrais etc.” (FOE, 2013, p. 219). Então, a desconexão do corpo em relação à emancipação do império representa um desafio à mediação e à transcendência dialética imediata das culturas com o seguinte objetivo: "a extração dolorosa do núcleo substancial, que será mais tarde submetido à consciência crítica do Outro e do mundo" (FOE, 2013, p. 219, grifos do autor). Isso sugere que a construção dos costumes, das religiões e dos saberes não devem atender às exigências exteriores, mas a uma produção a partir da própria localidade que apreende as necessidades inerentes à própria cultura.

No segundo elemento, "os homens e mulheres africanos devem demonstrar que tendo sido um povo que foi submetido e conduzido por Outros recuperou a capacidade 
de conduzir seu próprio destino" (NASCIMENTO, 2002, p. 54), o autor explica a importância de as sociedades africanas e seus descendentes da diáspora se localizarem no mundo não por meio das construções teóricas que as subalternizaram, mas por aquelas que permitem a autossuficiência pan-africana. O pan-africanismo simboliza, para o autor, a atitude de observação de toda e qualquer sociedade africana como pertencente ao mesmo tronco apesar de suas ramificações, com a intenção de formar a unidade cultural:

Fica claro então que a edificação de mecanismos transculturais no coração da comunidade pan-africana é passo fundamental que virá garantir a realização do pan-africanismo se estiverem integrados num projeto progressista econômico, político e social. Futuros passos sobre estradas pragmáticas deverão procurar os meios de enfatizar e desenvolver a cultura pan-africana e nunca, de meramente promover, por exemplo, a cultura afro-brasileira, a cultura ioruba, a haitiana, ou qualquer outra cultura negro-africana singular (NASCIMENTO, 2019, p. 95).

Por tais particularidades, Nascimento entende que a resistência africana perante as vicissitudes colonialistas e racistas precisam de uma construção que destaque a condução do próprio destino. Disso emerge a autossuficiência que denota a autonomia e a capacidade de cada país determinar-se diante da própria emancipação: "Devemos começar imediatamente a reconhecer nossa dependência de nós próprios, explorar nosso potencial de força e recursos, estudar e conhecer nossa circunstância, controlar nossas energias e riquezas" (NASCIMENTO, 2002, p. 69).

Assim, haveria uma política cultural que impediria e evitaria o avanço da luta dos povos africanos e dos povos afrodiaspóricos contra qualquer tipo de opressão, exploração e racismo. Um desses impedimentos situa-se na linguagem, pois "dentro do sistema de barreiras interpondo-se entre nós, existe este absurdo fato de necessitarmos usar em nossa comunicação recíproca a língua dos opressores” (NASCIMENTO, 2002, p. 70). Tal estratégia em primeiro momento produz uma aparência que não implica uma separação entre os povos africanos, mas o autor alerta que esta circunstância linguística consistiria, por exemplo, na ausência de negros/as brasileiros/as nos primeiros Congressos Panafricanos $5^{5}$ " "neste fato temos uma trágica instância da separação a nos imposta pelas barreiras linguísticas construídas pelo colonialismo" (NASCIMENTO, 2002, p. 70).

\footnotetext{
${ }^{5}$ Houve no século XX cinco grandes Congressos Pan-africanistas que tinham o objetivo de reunir intelectuais negros e negras de países africanos e da diáspora. Contudo, o V Congresso realizado em Manchester no ano de 1945 tornou-se o mais emblemático, pois os organizadores Kwame Nkrumah (então presidente de Gana) e George Padmore redigiram um documento que afirmava a decisão de libertação por parte dos povos coloniais: "O Quinto Congresso Panafricano põe aos intelectuais e às classes professionais
}

Revista da ABPN • v. 12, n. $31 \cdot \operatorname{dez} 2019$ - fev 2020, p. 133-151 
Essas construções possuem similaridades com o que Foé argumenta como sendo "retomada da iniciativa histórica", cuja finalidade é "edificar um polo autônomo de potência capaz de dialogar na perfeita igualdade com os outros povos do mundo" (FOE, 2013, p. 223). Tal retomada tem como referência Aimé Césaire por defender que o povo colonizado tendo a sua unidade cultural rompida por efeito do colonialismo, precisaria construir uma nova unidade, mesmo não sendo possível em um regime colonial "porque só se pode esperar tal mistura, tal remistura de um povo, quando este conserva a iniciativa histórica; dito de outro modo, quando este povo é livre" (CÉSAIRE, 2011, p. 269). Com isso, Foé (2013, p. 223) argumenta que "é preciso então nos ater ao essencial, que é a questão das condições políticas do diálogo das culturas”. Essas condições implicam um “compromisso imediato com o Outro [que] ocorre sem uma negociação prévia dos termos do acordo. É o sentido último da adaptação das culturas ao vasto mundo e da mestiçagem" (FOE, 2013, p. 219, grifos do autor) e, por causa disso o "mundo", ao tornarse global também se torna frágil no sentido das identidades se fragmentarem. Por consequência, para Foé, a aparente saída do colonialismo resultou, na verdade, em um “comodismo" por impossibilitar o diagnóstico de antagonismo, já que o discurso hegemônico movimenta-se a partir de então em "um universo de onde foi suprimido (artificialmente) o antagonismo fundamental entre o Norte opressor e o Sul oprimido, o centro desenvolvido e rico e a periferia subdesenvolvida e pobre; o Ocidente explorador e a África explorada" (FOE, 2013, p. 220).

Por essa ausência de conflitos, o autor explica a existência de dois caminhos diante dessa configuração global: ou uma adaptação perante o mundo através das qualidades essenciais (essência, escravo, colonizado, operário, camponês, animista, etc), ou uma afirmação e uma resistência de si para expor a personalidade histórica diante das falácias desenvolvimentistas. Assim, a "retomada da iniciativa histórica" aproxima-se do conceito de autossuficiência de Abdias de Nascimento por este último ser um conceito mitopoético, “isto é, no espaço profundo onde a cultura exerce uma função crítica imanente ao seu fundamento criativo e libertador do ser humano e da sociedade nacional"

das colônias que tomem consciência de suas responsabilidades. A larguíssima noite tem terminado. Ao lutar por direitos sindicais, pelo direito de formar cooperativas, pela liberdade de imprensa, de reunião, de manifestação e de greve, pela liberdade de editar e de ler a literatura necessária para a educação das massas, estareis utilizando os únicos meios que permitirão adquirir e conservar vossas liberdades. Hoje só existe um caminha para ação eficaz: a organização das massas” (NKRUMAH, 1965, p. 134). 
(NASCIMENTO, 2002, p. 54) e, diante disso, consolida-se outra dialética entre as culturas.

Não obstante, o terceiro elemento para construção do Quilombismo tem como perspectiva uma saída das amarras colonialistas que impõem, conforme o autor, uma segregação entre os povos africanos e aceitação de um destino servil. Com isso, a aplicação das diretrizes do Quilombismo promove um poder e um desejo de "libertar a si mesmos daqueles instrumentos estrangeiros, de dominação que no passado os oprimiram e alienaram; e que vigorosa e decididamente rejeitam todas as forças de exploração e submissão" (NASCIMENTO, 2002, p. 55). Em outras palavras, uma reação ao epistemicídio provocado pelo racismo epistêmico. Por esse sentido, esta pesquisa compreende o projeto histórico científico do Quilombismo como uma maneira de descolonização epistêmica. Este conceito, de acordo com o filósofo brasileiro Wanderson Flor do Nascimento (2009), corresponde à validade de um discurso filosófico a partir de um conhecimento pluritópico e com desenvolvimento científico abarcado em várias geografias, já que o hegemônico adequa as produções do globo por meio de um padrão euro-norte-americano:

Os argumentos de constituição dos currículos normalmente se ancoram nos critérios de 'importância' (ou relevância), que estariam ligados com a possibilidade de que os conceitos estudados possam compreender realidades gerais, universais, e também com a contribuição das reflexões filosóficas ao desenvolvimento da ciência, na 'potência' da epistemologia. Isso se converte em um critério de exclusão de publicização de produções. Muitas vezes, as filosofias 'africanas', 'asiáticas', 'latino-americanas' aparecem como tópicos complementares, de importância menor, quando não exotizadas, apresentando uma forma metafilosófica da diferença colonial, mostrando que essas filosofias precisam ainda ser desenvolvidas para alcançarem o status do pensamento euronorteamericano (FLOR DO NASCIMENTO, 2009, p. 9).

Desse modo, para o autor, uma filosofia descolonizada teria que pensar não apenas o local, mas desde o local, isto é, "pensando estratégias que, atentas ao modo eurocêntrico de produzir conhecimento e filosofia, estejam vinculadas a um projeto de liberar o pensamento das amarras da colonialidade" (FLOR DO NASCIMENTO, 2009, p. 10). Tais amarras contribuíram para a ampliação de uma Modernidade que interfere nas práticas sociais, na política, na ética, no conhecimento cotidiano e nas diversas ciências: 
É na Modernidade que vemos surgir um específico modo de exercício de poder, que tem uma específica maneira de articular conhecimentos para a validação desse modo de exercer o poder, fundado em uma geopolítica, o que indica que esses modos de produção de conhecimento e de exercício de poder têm um local privilegiado de irradiação e atuam de modos diferentes em diferentes lugares do mundo (FLOR DO NASCIMENTO, 2009, p. 2).

Por esse viés, o Quilombismo de Abdias do Nascimento contribui para descolonizar a percepção do africano e seus descendentes perante o Estado eurocêntrico, por ser aquele que propaga uma única e idêntica significação: um estado de terror organizado contra as pessoas negras. Essa maneira de extermínio ocorre de diferentes modos, seja através da hierarquização de uma estética branco-europeia, seja na idealização de cultura e civilização. No interesse de construir essas concepções, a pessoa negra permanece à margem da sociedade ocidental e o principal efeito é o entendimento dessa personalidade como "natural". Desse modo, para o autor, uma vez consciente dessa armadilha ideológica ela não deve se acomodar diante de conquistas sociais ou de direitos civis, pois há uma compreensão muito mais ampla nos discursos conformistas:

[a pessoa negra] já compreendeu que terá de derrotar todos os componentes do sistema ou da estrutura vigente, inclusive a sua intelligentsia responsável pela cobertura ideológica da opressão através da teorização 'científica' seja de sua inferioridade biossocial, da miscigenação sutilmente compulsória ou da criação do mito da 'democracia racial'. Essa 'intelligentsia', aliada a mentores europeus e norte-americanos, fabricou uma 'ciência' histórica ou humana que ajudou a desumanização dos africanos e seus descendentes para servir os interesses dos opressores eurocentristas. Uma ciência histórica que não serve a história do povo de que trata está negando-se a si mesma. Trata-se de uma presunção cientificista e não de uma ciência histórica verdadeira (NASCIMENTO, 2019, p. 287).

Com essas palavras pode-se notar como a proposta do Quilombismo aponta para a característica flexível e criativa das culturas africanas de incorporar os valores “científicos" e/ou "progressistas" de outras culturas para que possam funcionar de acordo com as exigências das próprias sociedades africanas ${ }^{6}$. Porém isso apenas tem relevância caso o nosso olhar dessa interação atente também para as contribuições que as culturas africanas possibilitaram às demais no mundo, já que "as culturas africanas, além de

\footnotetext{
${ }^{6} \mathrm{Ou}$ conforme Kwame Nkrumah ao definir o consciecismo, uma forma de encaixa-los na personalidade africana: "Consciencismo é o mapa em termos intelectuais da disposição das forças que vai permitir para a sociedade Africana digerir (to digest) o Ocidente e os elementos Islâmicos e Euro-Cristãos na África, e desenvolvê-los de tal forma que eles se encaixam na personalidade Africana" (NKRUMAH, 1970, p. 35).
} 
conterem sua intrínseca e valiosa ciência, também oferecem uma variedade de sabedoria necessária, pertinente a nossa existência orgânica e histórica" (NASCIMENTO, 2002, p. 56). Com isso, o autor explica como o Quilombismo se tornaria um instrumento conceitual operativo que privilegiaria o local em detrimento de uma busca de princípios globais, pois o ambiente colonizado pode facilmente se esquecer de que as formações desses princípios se deram em contextos e realidades diferentes. Por isso, a manutenção de conceitos, definições e princípios devem se relacionar com a vivência, a cultura e a ação concreta da coletividade negra com a intenção de intensificar a capacidade de luta e de resistência. Desse modo, Nascimento destaca o Quilombismo como uma ciência histórica-humanista que possibilita a resistência da população negra:

Precisamos e devemos codificar nossa experiência por nós mesmos, sistematizála, interpretá-la e tirar desse ato todas as lições teóricas e práticas conforme a perspectiva exclusiva dos interesses das massas negras e de sua respectiva visão de futuro. Esta se apresenta como a tarefa da atual geração afro-brasileira: edificar a ciência histórico-humanista do Quilombismo (NASCIMENTO, 2019, p. 289).

Essa edificação é necessária, pois, conforme o autor, as ciências humanas ministradas em nossos centros de excelência têm como fundamento povos e contextos socioeconômicos diferentes dos povos africanos e dos descendentes da diáspora africana na América. Isso tornaria, por exemplo, a etnologia, economia, a história, a antropologia, a filosofia, todas com pouca ou nenhuma utilidade para colaboração ao conhecimento dos povos negros: "o conhecimento científico que os negros necessitam é aquele que os ajude a formular teoricamente - de forma sistemática e consistente - sua experiência de quase quinhentos anos de opressão" (NASCIMENTO, 2019, p. 287).

Ainda assim, Nascimento alerta para a existência de erros e equívocos inevitáveis na tentativa de expor uma racionalidade de sistemas de valores sobre o esforço de autodefinição da própria personalidade negra e do caminho de tais povos. Isso em parte pela influência da ciência eurocêntrica que impôs dogmas e marcaram a mente colonizada. Por isso, toda a manifestação libertadora dessas marcas é recenseada pelos setores privilegiados da sociedade. Por outro lado, para Nascimento essas manifestações contrárias apenas demonstram como "a lavagem cerebral que pretendia tirar a nossa humanidade, a nossa identidade, a nossa dignidade, a nossa liberdade" (NASCIMENTO, 2019, p. 289) entrou em falência e, por isso, é necessária a libertação Quilombista: 
Quilombo não significa escravo fugido. Quilombo quer dizer reunião fraterna e livre, solidariedade, convivência, comunhão existencial. Repetimos que a sociedade quilombola representa uma etapa no progresso humano e sócio-político em termos de igualitarismo econômico. Os precedentes históricos conhecidos confirmam esta colocação. Como sistema econômico, o Quilombismo tem sido a adequação ao meio brasileiro do comunitarismo e/ou ujamaaísmo da tradição africana (NASCIMENTO, 2019, p. 289-290).

E a maior contribuição do Quilombismo seria realizar uma conjugação entre os mecanismos operativos do sistema e os diversos níveis da vida coletiva. No interior desse coletivo é que permaneceria a dialética que busca a realização completa do ser humano sem uma distinção entre grupos humanos, já que historicamente a experiência dos africanos na diáspora foi e é permeada por um conteúdo essencialmente racista que tenta atenuar a escravização e similares ações desumanizadoras como efeitos de um subproduto capitalista: "assim a escravização dos africanos e a desumanização dos seus descendentes nas Américas ocorreram e ocorrem como um determinismo inarredável do processo econômico da humanidade" (NASCIMENTO, 2019, p. 294).

Esse processo formula, conforme o autor, uma "necessidade" na mente dos colonizados de maneira que compreendem a escravidão como uma parte do sistema de produção. Mas não somente isso, também a compreendem como um "desígnio irrecorrível de Deus ou das potências cósmicas" (NASCIMENTO, 2019, p. 294). No entanto, esse processo é parte de uma racionalização que atua nas motivações, aspirações e interesses dos seres humanos, de forma que o racismo se consolida como um elemento existencial sofrido pelos povos negros:

Tanto se faz uso da violência policial direta e brutal, quanto da violência ideológica sutil, ou da violência econômica que é uma forma de genocídio físico e espiritual. Todas as formas imagináveis de coação se praticaram e se praticam, inclusive a violência religiosa, no afã de assegurar a imposição ariano-ocidental sobre os afro-brasileiros. (NASCIMENTO, 2019, p. 295).

Por esse aspecto, Nascimento contribuiu para uma leitura do projeto quilombista como uma proposta de resistência e uma construção teórica que se contrapõe ao epistemicídio que o colonialismo e o racismo provocaram na produção de conhecimento de africanos e de descendentes da diáspora.

\section{CONSIDERAÇÕES FINAIS}


Este artigo consistiu em um breve apontamento de como o pan-africanismo influenciou a militância e a produção intelectual de Abdias de Nascimento e como propiciou um exercício de descolonização epistêmica. As características polemistas e diplomáticas de Marcus Garvey e Kwame Nkrumah consistem em uma das posições que fundamentaram a compreensão da necessidade de uma unidade africana não somente dos povos dos continentes africanos, mas também daqueles povos diaspóricos de ascendência africana nas Américas e na Índia Ocidental. No que se refere ao Brasil, Abdias Nascimento explica que a nossa história precisa ser pensada por meio das contribuições negras para a nossa formação ${ }^{7}$ :

A história do Brasil é uma versão concebida por brancos, para os brancos e pelos brancos, exatamente como toda sua estrutura econômica, sócio-cultural, política e militar tem sido usurpada da maioria da população para o benefício exclusivo de uma elite branca/brancóide, supostamente de origem ário-europeia. Temos de considerar que a informação disponível nos Estados Unidos e, aliás, em quase todo o mundo, conduz a esse tipo de confusão. Citarei rapidamente, para ilustrar, os Negros Brasil, de Donald Pierson, e Casa Grande e Senzala, de Gilberto Freyre. Ambos fornecem uma visão suave, açucarada, das relações entre negros e brancos no país (NASCIMENTO, 2019, p. 35).

Tal idealização histórica brasileira não apenas oculta o real contato existente no Brasil entre brancos e negros, mas intensifica o imaginário coletivo acerca do ímpeto violento e selvagem direcionado à população negra. Por outro lado, alguns setores da sociedade brasileira forjam relações entre brancos e negros por meio da visão harmônica entre as "raças". Por efeito, há refutação de qualquer possibilidade para afirmação e resistência da consciência negra em prol da "consciência humana". Contra isso, Abdias afirma: "Não aceito o escapismo da 'humanidade sem cor', que simplesmente nos conduz ao endosso de nossa alienação cultural e racial, tão persistentemente patrocinada e advogada por aquelas ideias e ideais do supremacismo eurocentrista" (NASCIMENTO, 2019, p. 104). Supremacia eurocentrista que funciona por meio da negação à África e aos africanos da sua história e quando é impossível a negação a estratégia é o embranquecimento (Egito Antigo) ou o ameaçador (religiões tradicionais).

Essas estratégias, para o autor, indicam a recusa de que os negro-africanos se reconheçam como tais e para que se envergonhem de sua identidade concreta. Para isso,

\footnotetext{
${ }^{7}$ Dessa maneira percebe-se a luta não somente de Abdias de Nascimento, mas de todos os movimentos negros em posicionar a história do Brasil contendo as contribuições dos povos africanos. Por isso, a implementação da lei 10.639/2003 que legisla o ensino de história e cultura afro-brasileira em todos os níveis de ensino simboliza a concretude de tais ações.
} 
Abdias constrói a partir de teses pan-africanistas resistência e alimento do orgulho da identificação negra-africana através da estética, da cultura e da religião. Com a expectativa de que "A revolução pan-africana deva assumir-se como tarefa prioritária a responsabilidade de garantir o resgate da consciência negra, a qual tem sido violada, distorcida e agredida de muitas formas e maneiras" (NASCIMENTO, 2019, p. 104).

Portanto, através dessa revolução que o pensamento de Abdias tornou-se um representante da luta contra o racismo anti-negro que a nossa "democracia racial" procura ocultar.

\section{REFERÊNCIAS BIBLIOGRÁFICAS}

CARNEIRO, Aparecida Sueli. A construção do Outro como não-ser como fundamento do ser. Tese (Doutorado em Educação), Universidade de São Paulo, São Paulo, 2005.

CESAIRE, Aimé. Cultura e colonização. In: SANCHES, Marcela Ribeiro. As malhas que os impérios tecem: textos anticoloniais, contextos pós-coloniais. Lisboa: Edições 70, 2011.

FANON, Frantz. Pele Negra, Máscaras Brancas. Salvador: EDUFBA, 2008.

FLOR DO NASCIMENTO, Wanderson. A modernidade vista desde o Sul: perspectivas a partir das investigações acerca da colonialidade. Padê: Est. em Filos., Raça, Gên.e Dir. Hum, Brasília, v. $1, \quad$ n. 1/2,p. 1-19, jan./dez, 2009. Disponível em: https://www.publicacoesacademicas.uniceub.br/pade/article/view/1071 Acesso em 17 de janeiro de 2020 .

FOE, Nkolo. Africa em diálogo, África em autoquestionamento: universalismo ou provincialismo? "Acomodação de Atlanta" ou iniciativa histórica? Educar em Revista, Curitiba, Brasil, n. 47, p. 175-228, jan./mar. 2013. Disponível em: https://revistas.ufpr.br/educar/article/view/31332 Acesso em 17de janeiro de 2020.

GARVEY, Marcus. A Estrela Preta. Brasil: Projeto Omega Nyahbinghi, 2010.

GARVEY, Marcus. African Fundamentalism. The Negro World. New York, Front Page Editorial, 1925.

MBEMBE, Achille. Necropolitica seguido de Sobre el gobierno privado indirecto. Madrid: Ed. Melusina, 2011.

MOORE, Carlos. Abdias do Nascimento e o surgimento de um pan-africanismo contemporâneo global. In: NASCIMENTO, Elisa Larkin do (Orga.). A Matriz Africana no Mundo. Sankofa I. São Paulo: Selo Negro, 2008.

NASCIMENTO, Carlos Roberto do. Abdias do Nascimento: o legado de um símbolo centenário. Revista da ABPN, v. 8, n.18, nov. 2015-fev. 2016, p.382-391. Disponível em: http://abpnrevista.org.br/revista/index.php/revistaabpn1/article/view/57/54. Acesso em $14 \mathrm{de}$ janeiro de 2020. 
NASCIMENTO, José Abdias de. O Genocídio do Negro Brasileiro: processo de um racismo mascarado. São Paulo: Ed. Perspectiva, 2016.

NASCIMENTO, Abdias do. O Quilombismo: documentos de uma militância pan-africanista. Petrópolis: Vozes, 1980.

NASCIMENTO, Abdias do. O Quilombismo: documentos de uma militância pan-africanista. Brasília: Fundação Cultural Palmares, 2002.

NASCIMENTO, José Abdias do. O Quilombismo: documentos de uma militância panafricanista. São Paulo: Ed. Perspectiva; Rio de Janeiro: Ipeafro, 2019.

NKRUMAH, Kwame. África debe unirse. Buenos Aires: EUDEBA, 1965.

NKRUMAH. Kwame. Consciencism: philosophy and ideology for de-colonization. Library of Congress, 1970.

Recebido 30/11/2019

Aprovado em: 30/01/2020 